\title{
Liquefaction potential analysis on runway construction based on soil engineering properties
}

\author{
Arif Maulana ${ }^{1}$, Rifa'i Ahmad ${ }^{1, *}$, and Faris Fikri ${ }^{1}$ \\ ${ }^{1}$ Department of Civil and Environmental Engineering, Universitas Gadjah Mada, Yogyakarta, Indonesia
}

\begin{abstract}
The term of liquefaction refers to a liquefied soil phenomenon during an earthquake causing the loss of soil bearing capacity. In general, liquefaction occurs in loose sandy soil with saturated condition triggered by an earthquake with Peak Ground Acceleration greater than $0.25 \mathrm{~g}$. This research aim to analyze the liquefaction potential of runway construction which located on loose sandy soil area. The analysis of liquefaction potential is based on borelog data, grain size distribution, soil physical properties, and earthquake risk map. The liquefaction potential was obtained by calculating the liquefaction probability in one dimension analysis determined as safety factor. Settle $3 D$ is also applied in this research. The results show that the liquefaction potentially occurs in sand soil layer at 0-6 meters depth with safety factor 0.11-1.06 from manual calculation and 0.19-1.1 from Settle 3D. This result represents high probability of liquefaction at runway construction area, so that the liquefaction prevention method is needed.
\end{abstract}

\section{Introduction}

Indonesia is the country with high concern in development of public transportation especially for the airport take off and landing services. The big effort to improve an airport take off and landing services is by constructing a new runway. Before starting to build the new one, soil investigation is the first important step which covers field and laboratory test to know about the geological condition of planned runway area. In the research area, the soil data consist of borelogs and also the laboratory test such as grain size distribution and soil physical properties.

According to the soil investigation data, the research area dominated by sandy and clayey soil with shallow ground water exist with depth less than $1.5 \mathrm{~m}$. In some cases, the SPT value of sandy soil from 0-6 $\mathrm{m}$ depth were measured within range 2-15. It means that there are some separated zones of loose-medium sand soil layer among the stratigraphic condition. The soil which composed with more than $65 \%$ fine sand grain [1] and less than $15 \%$ silt or clay grain [14] probably has high liquefaction potential. Therefore, the presence of saturated loose sand soil in spotted zone of the runway construction area make it probably has high liquefaction potential. Besides, Indonesia is the country with frequently occurence of medium to high magnitude earthquake. The research area potentially has $0,5 \mathrm{~g}$ of Peak Ground Acceleration value which determined by the earthquake risk map of Indonesia. It means that the area is seismically high and potentially trigger the occurence of liquefaction. Therefore, the evaluation of the liquefaction potential in the research area is needed to know how far the liquefaction occurence possibility.

This research aim to understand the liquefaction potential based on the safety factor value. The safety factor value obtained from manual calculation and by using Settle $3 D$. Both analysis will be conducted by using the method suggested by Seed (1983). The field and laboratory data will be used in the analysis as the input parameters.

\section{Literature Review}

\subsection{Regional Geology}

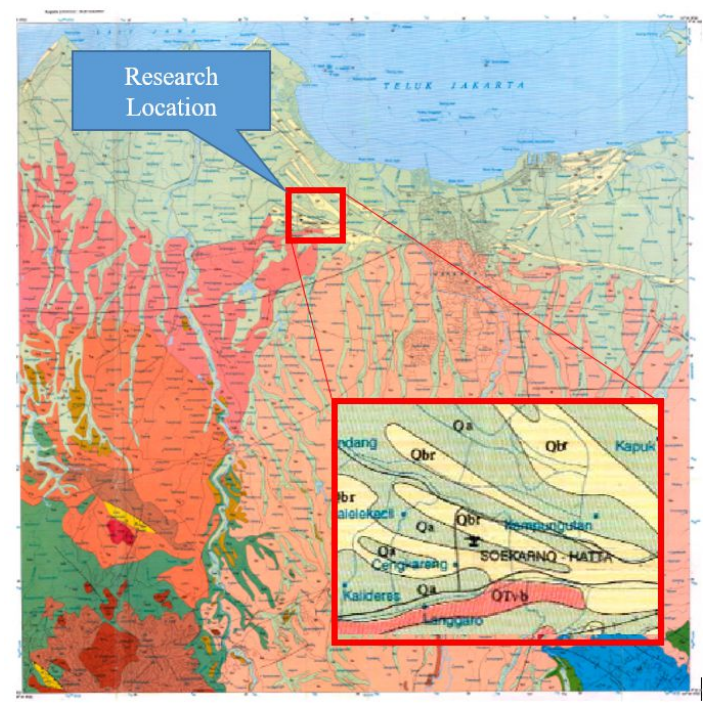

Fig. 1. Geological map of research area.

\footnotetext{
* Corresponding author: ahmad.rifai@ugm.ac.id
} 
The geological condition of the research area will be explained in geomorphology, stratigraphy, and tectonic aspects. Geomorphology is a branch of geological science that learn about the morphology of earth surface include description, zone distribution, and genesis (the way it happened). The research area located in the downstream of the West Java deposition that have a south to north depositional direction. The presence of loose sediment deposit with shallow ground water level in this area is the main result of fluvial process. This area categorized as fluvial landscape [12].

According to Fig. 1, the stratigraphic condition of the research area was covered by three geological formations from the bottom to the top, they are Tuff Banten Formation (QTvb), Beach Ridge Deposits (Qbr), and Alluvium (Qa). The Tuff Banten Formation consist of tuff, pumice tuff, and tuffaceous sandstone, the Beach Ridge Deposits consist of fine to coarse sand with mollusk shell, and the Alluvium consist of soil with varies grain size from clay to gravel [13].

The tectonic condition describe the earthquake potential of an area. As we know, Indonesia is located in "ring of fire" which formed as a result of the collision from 3 major plates (Indo-Australian, Pacific, and Eurasian). The oceanic crust is moving then crashing the continental crust. It caused by the convection-heat flow from the asthenosphere. Because of the greater density of the oceanic crust, it falls down below the continental crust. This activity triggered the occurrence of the earthquake. Besides that, the presence of fault or joint also can make an area has more dangerous effect from the earthquake. From the Fig. 1 also, there is no fault or joint exist in the research area. It signifies the earthquake has low dangerous effect but need to inspect the soil behavior due to liquefaction potential.

\subsection{Liquefaction}

The term of liquefaction is a liquefied phenomenon of saturated loose sandy soil caused by cyclic load due to an earthquake with peak ground acceleration greater than $0.25 \mathrm{~g}$ [11]. It makes a loss of soil bearing capacity after the increasing of pore water pressure and also followed by decreasing of soil effective stress [4]. It can be expressed as the Equation 1. The failures caused by liquefaction could be also sand boil, lateral spreading, and ground oscillation [5].

$$
\sigma^{\prime}=\sigma-u
$$

Where $\sigma^{\prime}$ is soil effective stress, $\sigma$ is total stress, and $u$ is the pore water pressure. Those parameters stated in $\mathrm{kPa}$ unit. The equation explain that the increasing of pore water pressure cause the decrease of effective stress. As the pore water pressure increase approach to the total stress value, the effective stress would be near to 0 . It means that liquefaction occur at this condition.

The liquefaction potential can be predicted by calculating the safety factor of soil against liquefaction. Seed (1983) described the safety factor value as the ratio of soil shear strenght with shear stress that caused by an earthquake. Soil shear strenght $\left(\tau_{\mathrm{h}}\right)$ can be determined by using Fig. 2. It shows the relationship between cyclic stress ratio $\left(\tau_{\mathrm{h}} / \sigma_{\mathrm{v}}\right)$ with the corrected SPT value $\left(N^{\prime}\right)$ where is obtained from Equation 2 and 3.

$$
\begin{aligned}
& N^{\prime}=C_{N} \cdot N_{F} \\
& C_{N}=9.78 \sqrt{\frac{1}{\sigma_{v}{ }^{\prime}}}
\end{aligned}
$$

Where $C_{N}$ is dimensionless correction factor, $\sigma_{v}{ }^{\prime}$ is vertical effective stress in $\mathrm{kPa}$, and $N_{F}$ is the SPT value in the field.

The parameter of shear stress affected by an earthquake $\left(\tau_{\mathrm{av}}\right)$ should be measured as comparison to the soil shear strenght parameter. This parameter can be calculated by Equation 4.

$$
\tau_{a v}=0.65 \cdot C_{D}\left[\left(\frac{\gamma h}{g}\right) \cdot a_{\max }\right]
$$

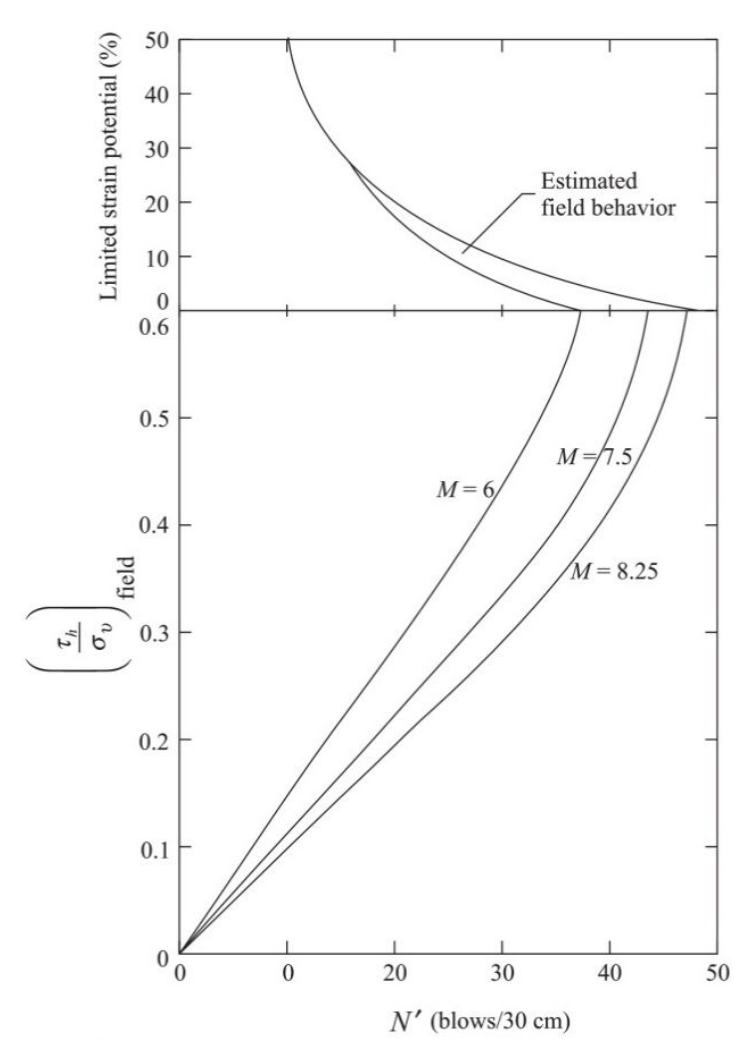

Fig. 2. Relationship between cyclic stress ratio $\left(\tau_{\mathrm{h}} / \sigma_{\mathrm{v}}\right)$ with $N^{\prime}$ value by Seed 1979 [4].

Where $C_{D}$ is shear stress reduction factor (obtained from Fig. 3), $\gamma$ is soil unit weight in $\mathrm{kPa}, h$ is depth of soil layer, and $a_{\max }$ is maximum ground acceleration.

Two important soil engineering properties in liquefaction potential analysis of this research are unit weight in wet condition $\left(\gamma_{b}\right)$ and unit weight in saturated condition $\left(\gamma_{\text {sat }}\right)$. Both parameters adopted from soil laboratory data and several suggestion from Table 1 and Table 2. 


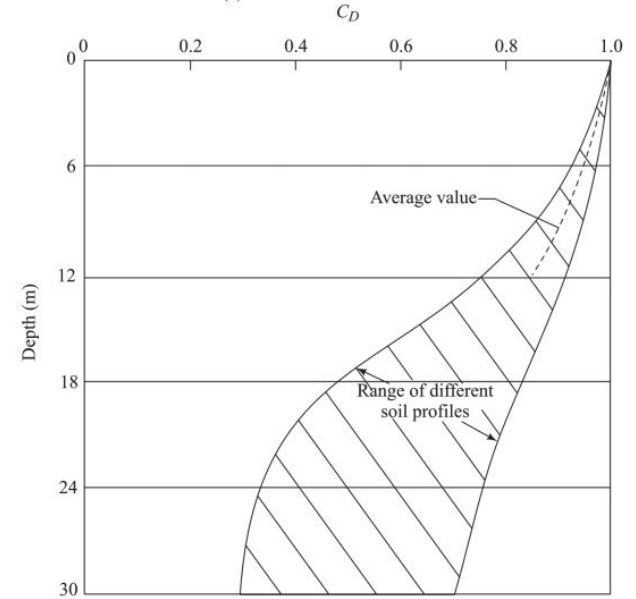

Fig. 3. Range of shear stress reduction factor $\left(C_{D}\right)$ in various depth by Seed and Idriss 1971 [4].

Table 1. Range value of $\gamma_{b}$ according to the $N_{F}$ value $[3,6,7]$

\begin{tabular}{ccc}
\hline Soil type & $N_{F}$ & $\gamma_{\mathrm{b}}\left(\mathrm{kN} / \mathrm{m}^{3}\right)$ \\
\hline Very loose sand & $<4$ & $<14$ \\
Loose sand & $4-10$ & $14-16$ \\
Medium sand & $10-30$ & $16-18$ \\
Dense sand & $30-50$ & $18-20$ \\
Very dense sand & $>50$ & $>20$ \\
\hline Very soft clay & $<2$ & $<15.7$ \\
Soft clay & $2-4$ & $15.7-18.8$ \\
Medium clay & $4-8$ & $17.3-19.6$ \\
Stiff clay & $8-16$ & $18.1-20.4$ \\
Very stiff clay & $16-32$ & $18.8-22$ \\
Hard clay & $>32$ & $>20.4$ \\
\hline
\end{tabular}

Table 2. Range value of $\gamma_{\text {sat }}$ of some soil types [8]

\begin{tabular}{cc}
\hline Soil type & $\gamma_{\text {sat }}\left(\mathrm{kN} / \mathrm{m}^{3}\right)$ \\
\hline Very loose sand & $16.67-17.65$ \\
Loose sand & $17.65-18.63$ \\
Medium sand & $18.63-20.59$ \\
Dense sand & $19.61-21.57$ \\
Very dense sand & $21.57-22.56$ \\
Soft clay & $16.67-18.63$ \\
NC clay & $17.65-21.57$ \\
OC clay & $19.61-23.54$ \\
\hline
\end{tabular}

\subsection{Peak Ground Acceleration}

According to AASHTO 2012 the liquefaction potential and loss of soil bearing capacity caused by an earthquake must be reviewed with peak ground acceleration which determined as Equation 5 [2].

$$
P G A_{\mathrm{M}}=F_{\mathrm{PGA}} \cdot P G A
$$

Where $P G A_{\mathrm{M}}$ is the adjusted peak ground acceleration, $F_{\mathrm{PGA}}$ is the site coefficient adopted from Table 3 , and $P G A$ is the peak ground acceleration value from Indonesian earthquake risk map.
Table 3. Site coefficient [2]

\begin{tabular}{ccccccc}
\hline Site & \multirow{2}{*}{$N_{F}$} & \multicolumn{5}{c}{$P G A$} \\
\cline { 3 - 7 } Class & & $\leq 0.1$ & 0.2 & 0.3 & 0.4 & $\geq 0.5$ \\
\hline SA & - & 0.8 & 0.8 & 0.8 & 0.8 & 0.8 \\
SB & - & 1.0 & 1.0 & 1.0 & 1.0 & 1.0 \\
SC & $>50$ & 1.2 & 1.2 & 1.1 & 1.0 & 1.0 \\
SD & $15-50$ & 1.6 & 1.4 & 1.2 & 1.1 & 1.0 \\
SE & $<15$ & 2.5 & 1.7 & 1.2 & 0.9 & 0.9 \\
\hline
\end{tabular}

\section{Method and Analysis}

\subsection{Data}

The research located in a runway construction area in Tanggerang, Indonesia. Borelog data and soil engineering properties from laboratory test are used in this research. DB-1 is the borelog with $20 \mathrm{~m}$ depth data used for liquefaction potential analysis also represent the sandy soil layer characteristics (Fig. 4). DB-1 will be correlated to DB-2 and DB-3 to know the soil stratigraphy vertically or horizontally.

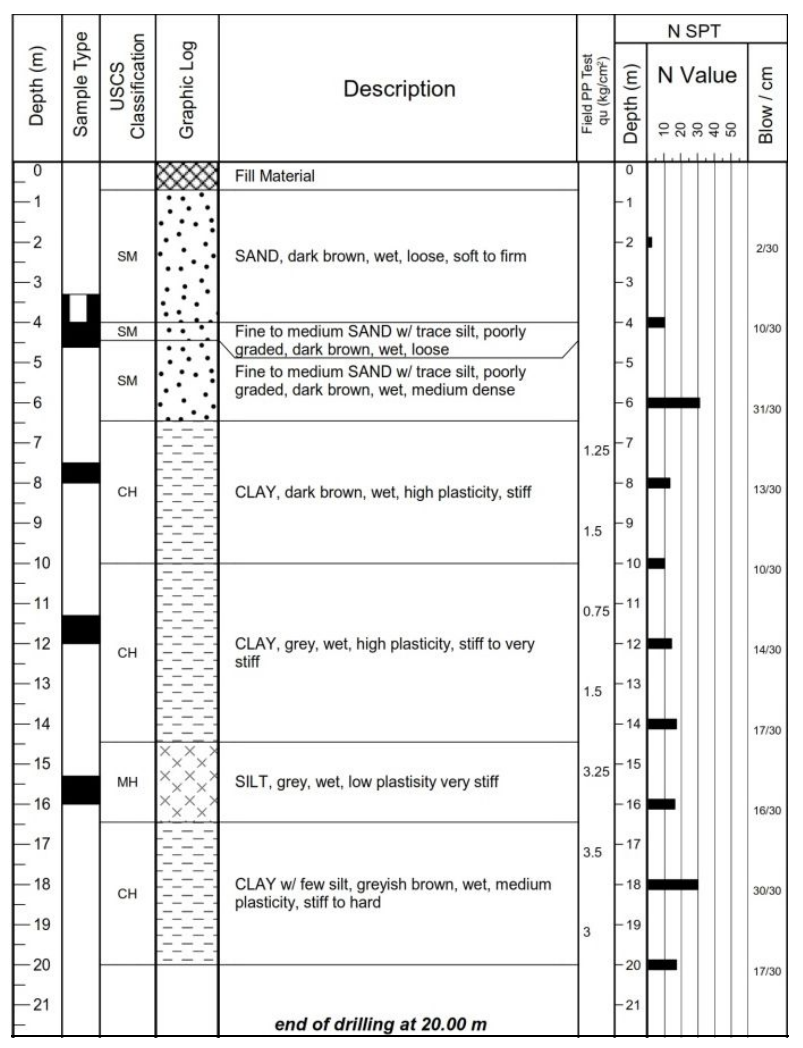

Fig. 4. DB-1 borelog data.

\subsection{Soil Characteristics and Stratigraphy}

According to the borelog data, the soil layer generally can be divided become two layers. From 0-6.5 m depth there are sand layer with SPT range value 2-31 and from $6.5-20 \mathrm{~m}$ there are clay layer with intercalation silt layer with SPT value range 10-30. 6 samples also were taken from different depth $(1 \mathrm{~m}, 3 \mathrm{~m}, 4 \mathrm{~m}, 7.5 \mathrm{~m}, 11.3 \mathrm{~m}$, and $15.3 \mathrm{~m})$. 


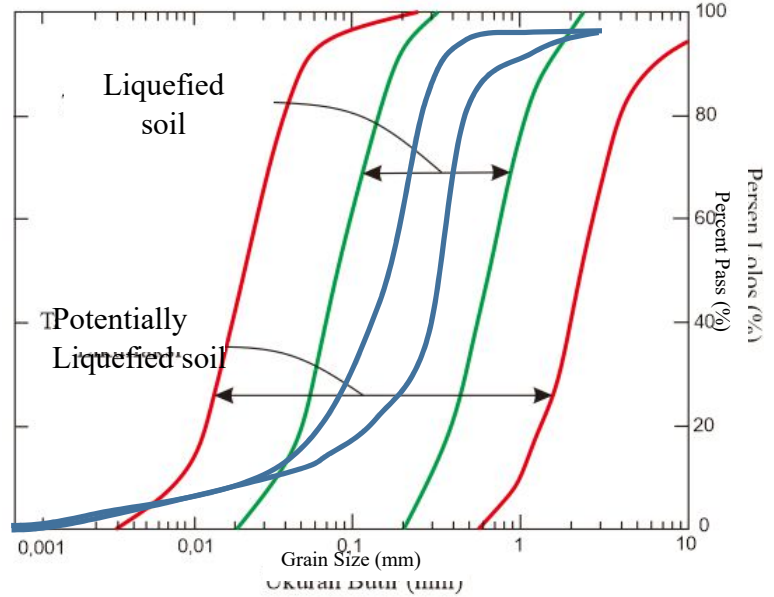

Fig. 5. Grain size distribution of sand layer of DB-1.

According to AASHTO soil classification and laboratory test, the clay layer classified as $\mathrm{CH}$ with fine grain percentage $97 \%$ and plasticity index value $52.54 \%$. The silt intercalation layer classified as $\mathrm{MH}$ with fine grain percentage $96.3 \%$ and plasticity index value $25.37 \%$. Furthermore, the sand layer classified as SM with fine grain percentage $13-15 \%$.

From Figure 5, the grain size distribution from two samples of sand layer in $1 \mathrm{~m}$ and $4 \mathrm{~m}$ depth of DB-1 (blue line) stand on the liquefied soil zone [9]. It means that the sand layer potentially high to be liquefied.

The stratigraphic condition of research area obtained from the correlation between 3 borelogs DB-1, DB-2 and DB-3 in $20,952 \mathrm{~m}^{2}$ area (see Fig. 6). The sand layer seems present in wedge shape to the northeast as it is not found in DB-2 and DB-3. In the bottom part, the clay layer still exist in DB-2 and DB-3 with the intercalation of silt layer. Beside that, the shallow groundwater level $(<1 \mathrm{~m}$ depth) also exist based on field measurement. This conditions possible to the occurence of liquefaction.

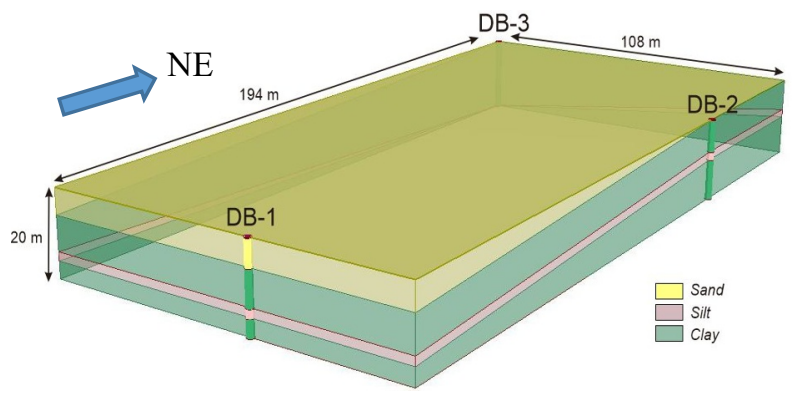

Fig. 6. Soil stratigraphy of research area.

\subsection{Liquefaction Potential Analysis}

Analysis for the liquefaction potential will be done in two different ways. The first one is by using manual calculation beside another one is by using software named Settle $3 D$ which is part of Rocscience. Seed method will be applied in both ways.

\subsubsection{Manual Calculation}

As mention above, there are two main parameters that is soil shear strenght $\left(\tau_{\mathrm{h}}\right)$ and soil shear stress induced by earthquake $\left(\tau_{\mathrm{av}}\right)$ in analysis of liquefaction potential. Firstly, the measurement of soil shear strenght need the data of soil effective unit weight $\left(\gamma^{\prime}\right)$ and SPT value from field $\left(N_{F}\right)$. Table 4 shows the data used and Table 5 shows the result of the measurement of soil shear strenght.

Table 4. Data used from DB-1

\begin{tabular}{ccccc}
\hline$z(\mathrm{~m})$ & Soil Type & $\begin{array}{c}\gamma_{\mathrm{b}} \\
\left(\mathrm{kN} / \mathrm{m}^{3}\right)\end{array}$ & $\begin{array}{c}\gamma^{\prime} \\
\left(\mathrm{kN} / \mathrm{m}^{3}\right)\end{array}$ & $N_{F}$ \\
\hline 2 & Very loose sand & 13.24 & 7.16 & 2 \\
4 & loose sand & 16 & 8.63 & 10 \\
6 & dense sand & 18.1 & 10.59 & 31 \\
\hline
\end{tabular}

Table 5. Calculation results of $\tau_{\mathrm{h}}$

\begin{tabular}{cccccc}
\hline$z(\mathrm{~m})$ & $\begin{array}{c}\sigma_{\mathrm{v}}{ }^{*} \\
(\mathrm{kPa})\end{array}$ & $C_{N}{ }^{* *}$ & $N^{* * * *}$ & $\tau_{\mathrm{h}} / \sigma_{\mathrm{v}} * * * *$ & $\tau_{\mathrm{h}}(\mathrm{kPa})$ \\
\hline 2 & 14.32 & 2.58 & 5 & 0.06 & 0.86 \\
4 & 31.58 & 1.74 & 17 & 0.19 & 6.00 \\
6 & 50.8 & 1.37 & 43 & 0.55 & 27.94 \\
\hline
\end{tabular}

$* \gamma^{\prime} . z,{ }^{*}$ Eq. $3,{ }^{* * *}$ Eq. $2,{ }^{* * * *}$ Fig. 2

After getting the soil shear strenght value, next step is calculate the soil shear stress induced by earthquake. Firstly, the earthquake must be determined and stated in peak ground acceleration value $\left(P G A_{\mathrm{M}}\right)$. In calculating the $P G A_{\mathrm{M}}$, as explained before, the $F_{\mathrm{PGA}}$ and $P G A$ value are needed for the calculation. $F_{\mathrm{PGA}}$ was obtained from Table 3. The site was classified as SE according to $N_{F}$ value $<15$ in general of sand layer in the research area. Furthermore, the $P G A$ of research area determined $0.5 \mathrm{~g}$ [10]. From that case, the $F_{\mathrm{PGA}}$ value is 0.9 . So, according to the Equation 5, the $P G A_{\mathrm{M}} 0.45 \mathrm{~g}$ is used.

The calculation result of soil shear stress induced by earthquake $\left(\tau_{\mathrm{av}}\right)$ shown in Table 6 . The result show that the range value of $\tau_{\mathrm{av}}$ is $7.67-26.31 \mathrm{kPa}$ from $0-6 \mathrm{~m}$ depth. In this calculation, the unit weight in wet condition $\left(\gamma_{b}\right)$ data adopted from Table 4 .

Table 6. Calculation results of $\tau_{\mathrm{av}}$

\begin{tabular}{ccccc}
\hline$z(\mathrm{~m})$ & $\sigma_{\mathrm{v}} *(\mathrm{kPa})$ & $C_{D}{ }^{* *}$ & $\mathrm{PGA}_{\mathrm{M}}$ & $\tau_{\mathrm{av}} * * *(\mathrm{kPa})$ \\
\hline 2 & 26.48 & 0.99 & 0.45 & 7.67 \\
4 & 58.48 & 0.97 & 0.45 & 16.59 \\
6 & 94.68 & 0.95 & 0.45 & 26.31 \\
\hline
\end{tabular}

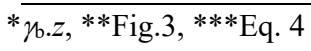

The degree of liquefaction potential reflected from $S F$ value which determined from ratio of soil shear strenght $\left(\tau_{h}\right)$ and soil shear stress induced by earthquake $\left(\tau_{\mathrm{av}}\right)$. Liquefaction occurs when the $S F$ value $<1$ which means that $\tau_{\mathrm{av}}$ is greater than $\tau_{h}$. Table 7 shows the result of liquefaction potential. Generally, the liquefaction occurs in all depth of sand layer from 0-6 m with $S F$ value range 0.11-1.06. Although the $S F$ value of dense sand is 1.06 (greater than 1), but it is critical to the occurance of liquefaction. 
a)

Table 7. $S F$ value for liquefaction potential

\begin{tabular}{ccccl}
\hline$z(\mathrm{~m})$ & $\begin{array}{c}\tau_{\mathrm{h}} \\
(\mathrm{kPa})\end{array}$ & $\begin{array}{c}\tau_{\mathrm{av}} \\
(\mathrm{kPa})\end{array}$ & $S F$ & Explanation \\
\hline 2 & 0.86 & 7.67 & 0.11 & Liquefaction \\
4 & 6.00 & 16.59 & 0.36 & Liquefaction \\
6 & 27.94 & 26.31 & 1.06 & Critical \\
\hline
\end{tabular}

\subsubsection{Settle 3D}

Settle $3 D$ is a software which part of Rocscience that can be used for liquefaction potential analysis. This tool generates the liquefaction probability as factor of safety. The parameters used in the analysis adopted from DB-1 borelog data. The first step of the analysis is determination of soil stratigraphy from DB-1 borelog data (Fig 7) also with parameters input of soil engineering properties (Table 8).

Table 8. Input of soil parameter

\begin{tabular}{ccccc}
\hline Soil Type & $\begin{array}{c}\gamma_{\mathrm{b}} \\
\left(\mathrm{kN} / \mathrm{m}^{3}\right)\end{array}$ & $\begin{array}{c}\gamma_{\text {sat }} \\
\left(\mathrm{kN} / \mathrm{m}^{3}\right)\end{array}$ & $\begin{array}{c}\text { Fine } \\
\text { grain } \\
(\%)\end{array}$ & $\begin{array}{c}\mathrm{D}_{50} \\
(\mathrm{~mm})\end{array}$ \\
\hline Very loose sand & 13.24 & 17.16 & 15.76 & 0.5 \\
Loose sand & 16 & 18.63 & 13.16 & 0.28 \\
Dense sand & 18.1 & 19.61 & - & -
\end{tabular}

The groundwater level is set in $0.9 \mathrm{~m}$ depth. The additional input parameters in Settle $3 D$ are fine grain percentage and $\mathrm{D}_{50}$ grain size of sand layer which not applicated in manual calculation.
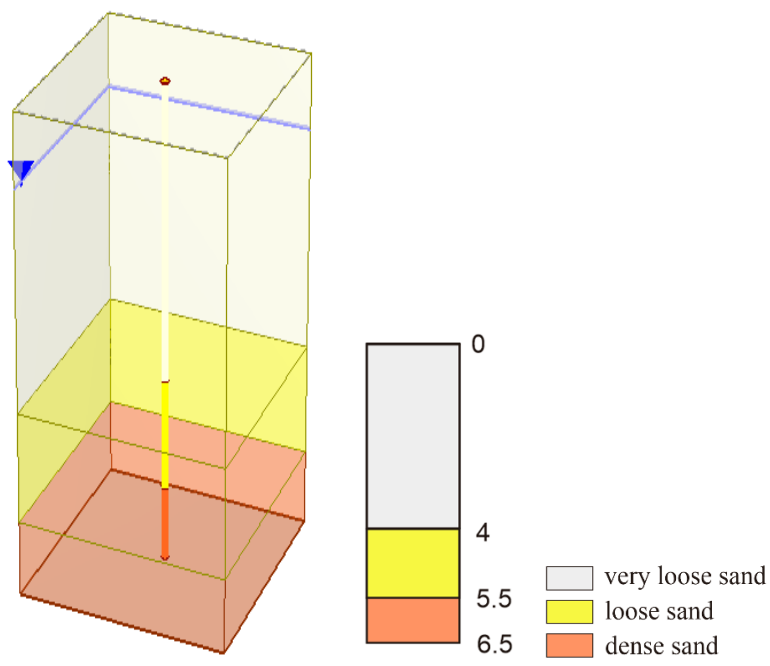

Fig. 7. The sand layer of DB-1.

The next step is input the parameters for liquefaction analysis. There are PGA value for earthquake parameter and SPT-field value for soil parameter. From Figure 8, the PGA value is set $0.45 \mathrm{~g}$ with earthquake magnitude 7.5. Slope angle was determined $0^{\circ}$ because the area is relatively flat. The input of SPT field value was obtained from borelogs data in $2 \mathrm{~m}$ depth interval.

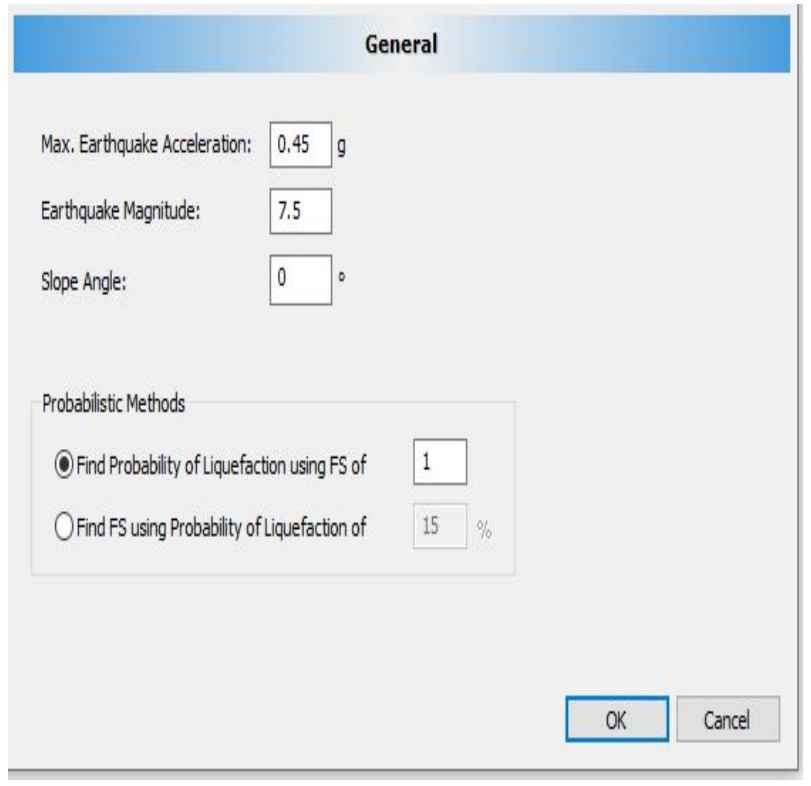

b)

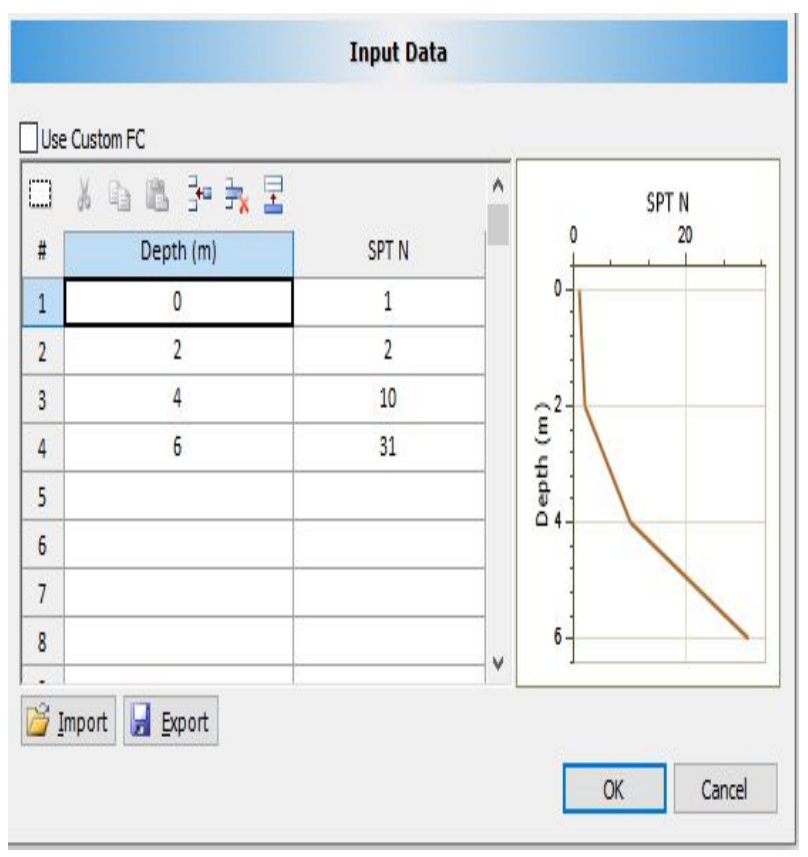

Fig. 8. Liquefaction analysis a) General input, b) SPT input.

Furthermore, the liquefaction analysis method was determined as Seed et al. (1984) method correspond to the manual calculation. There are 8 methods that can be used for the liquefaction potential analysis. The result of analysis show that the range of the safety factor against liquefaction is 0.19-1.1 from 0-6 $\mathrm{m}$ depth (see Fig. 9).

According to the both ways of liquefaction potential analysis. The result show that there is no significant difference between manual calculation and Settle $3 D$ calculation. The results of the liquefaction potential analysis using Settle $3 D$ software compared to the results of analysis with manual calculations (Fig. 10). It is seen that the SF value of each method is relatively similar, marked by a coinciding curve. 


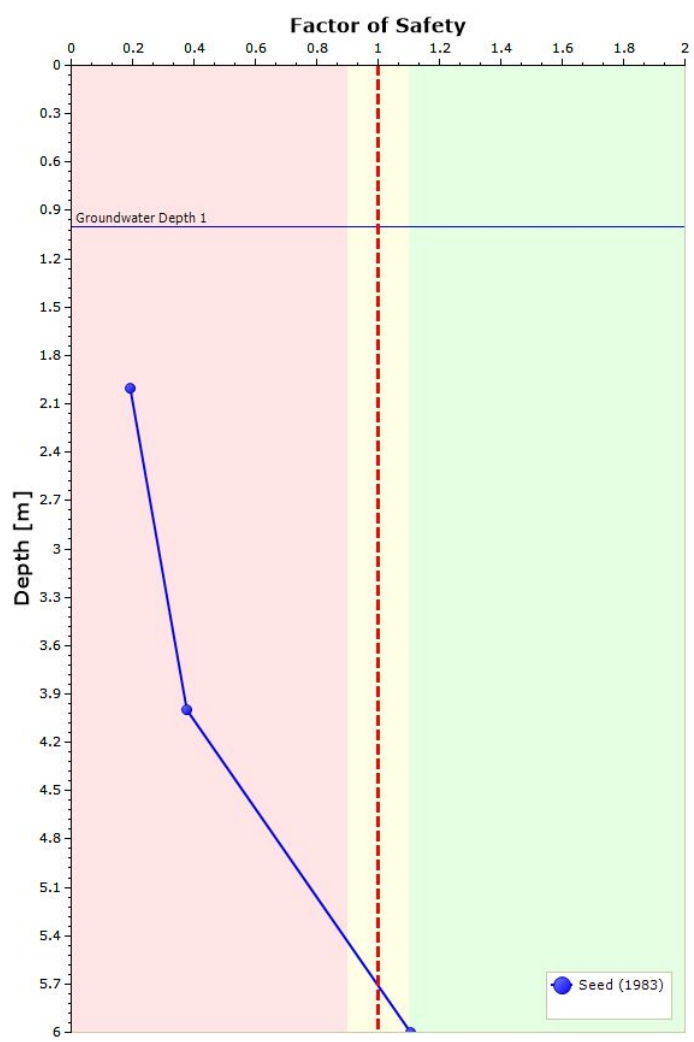

Fig. 9. Factor of safety against liquefaction curve from Settle $3 D$ result.

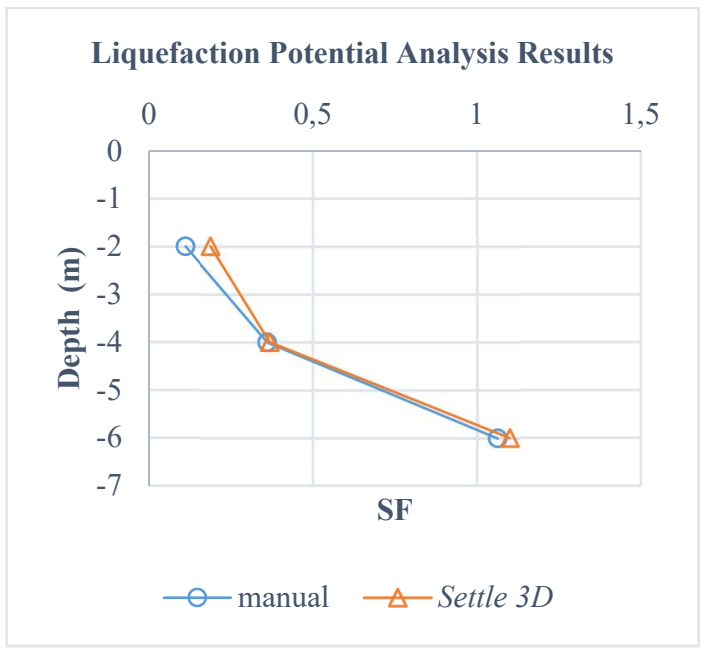

Fig. 10. Comparison of $S F$ value between manual calculation and Settle $3 D$.

\section{Conclusions}

According to the analysis of stratigraphy, there is a very loose-dense sand layer with thickness around 4-6 $\mathrm{m}$ in saturated condition. The sand layer is horizontally thinner through to northeast. This soil condition probably has high liquefaction potential.

The results of the liquefaction potential analysis are the $S F$ value ranged from $0.11-1.06$ by manual calculation and $0.19-1.1$ by using Settle $3 D$. The difference in the calculation results between the two methods is not much different. It is indicated that the sand layer in the research area is susceptible to the liquefaction where the PGA value is $0.45 \mathrm{~g}$. So the liquefaction prevention method is needed.

\section{References}

1. A. Hakam, E. Suhelmidawati, Liquefaction Due to September 30 2009 Earthquake in Padang. (Elsevier, 2013)

2. Badan Standardisasi Nasional, SNI 8460:2017 Tata Cara Perencanaan Ketahanan Gempa untuk Struktur Bangunan Gedung dan Non Gedung. (Jakarta: BSN, 2017)

3. British Standard 5930, Code of Practice for Site Investigations. (London: British Standards Institution, 1981)

4. ]B. M. Das, G.V. Ramana, Principles of Soil Dynamics second edition. (Stamford: Cengage Learning, 2011)

5. Committee on Earthquake Engineering, Liquefaction of Soil During Earthquakes. (Washington D.C: National Academy Press, 1985)

6. J.E. Bowles, Foundation Analysis and Design. (New york: McGraw-Hill Inc, 1977)

7. K. Terzaghi \& R.B. Peck, Soil Mechanics in Engineeriing Practice. (New York: John Wiley \& Sons, Inc., 1967)

8. M. Carter, S.P. Bentley. Correlations of Soil Properties. (London: Pentech Press, 1991)

9. O. Aydan, R. Ulusay, V.O Atak, Evaluation of Ground Deformations Induced by the 1999 Kocaeli Earthquake (Turkey) at Selected Sites on Shorelines. (Springer Verlag, 2008)

10. Pusat Studi Gempa Nasional, Peta Sumber dan Bahaya Gempa Indonesia 2017. (Bandung, 2017)

11. S. Toprak, T.L. Holzer, Liquefaction Potential Index: Field Assessment. (California: ASCE, 2003)

12. Srijono, S. Husein, G.I. Marliyani, Geomorfologi: Proses dan Klasifikasi Bentang Alam. (Yogyakarta: Jurusan Teknik Geologi FT UGM, 2007)

13. T. Turkandi, Sidarto, D.A. Agustiyanto, P. Hadiwidjoyo, Peta Geologi Lembar Jakarta dan Kepulauan Seribu, Jawa. (Bandung: Pusat Penelitian dan Pengembangan Geologi, 1992)

14. W.S. Wang, Some Findings in Soil Liquefaction. (Beijing: Water Conservancy and Hydroelectric Power Scientific Research Institute, 1979) 